\title{
Upwind Dynamic Soaring of Albatrosses and UAVs
}

\author{
Philip L. Richardson \\ Department of Physical Oceanography MS\#29 \\ Woods Hole Oceanographic Institution \\ 360 Woods Hole Road \\ Woods Hole, MA 02543 USA \\ May 21, 2014 \\ E-mail address: prichardson@whoi.edu \\ Tel: 5082892546 (W), 5085402648 (H) \\ Fax: 5084572163
}




\begin{abstract}
Albatrosses have been observed to soar in an upwind direction using what is called here an upwind mode of dynamic soaring. The upwind mode is modeled using the dynamics of a two-layer Rayleigh cycle in which the lower layer has zero velocity and the upper layer has a uniform wind speed of $W$. The upwind mode consists of a climb across the wind-shear layer headed upwind, a $90^{\circ}$ turn and descent across the wind- shear layer perpendicular to the wind, followed by a $90^{\circ}$ turn into the wind. The increase of airspeed gained from crossing the wind-shear layer headed upwind is balanced by the decrease of airspeed caused by drag. Results show that a wandering albatross can soar over the ocean in an upwind direction at a mean speed of $8.4 \mathrm{~m} / \mathrm{s}$ in a $3.6 \mathrm{~m} / \mathrm{s}$ wind, which is the minimum wind speed necessary for sustained dynamic soaring. The main result is that an albatross can soar upwind much faster that the wind speed. The upwind dynamic soaring mode of a possible robotic albatross UAV (Unmanned Aerial Vehicle) is also modeled using a Rayleigh cycle. Maximum possible airspeeds are approximately equal to 9.5 times the wind speed of the upper layer. In a wind of $10 \mathrm{~m} / \mathrm{s}$, the maximum possible upwind (56 m/s) and across-wind (61 m/s) components of UAV velocity over the ocean result in a diagonal upwind velocity of $83 \mathrm{~m} / \mathrm{s}$. In sufficient wind, a UAV could, in principle, use fast diagonal speeds to rapidly survey large areas of the ocean surface and the marine boundary layer. Limitations to achieving such fast travel velocity are discussed and suggestions are made for further studies.
\end{abstract}

Keywords: dynamic soaring, energy-neutral soaring, albatross, robotic albatross, Unmanned Aerial Vehicle, UAV

\title{
Highlights:
}

- Dynamic soaring of albatrosses and UAVs was simulated with a two-layer dynamic model.

- Observed upwind dynamic soaring of albatrosses was successfully modeled.

- Upwind dynamic soaring of a robotic albatross UAV was simulated with the same model.

- A UAV is able to soar upwind much faster than an albatross due to superior strength. 
- A possible fast UAV survey mode uses parallel diagonal tracks relative to wind.

\section{Introduction}

On a research cruise to the South Atlantic I watched with amazement as a wandering albatross soared upwind parallel to our ship, which was steaming upwind at $6 \mathrm{~m} / \mathrm{s}$ (12 knots) into a $7 \mathrm{~m} / \mathrm{s}$ head wind. The bird came from leeward of the ship and caught up with us, indicating it was soaring significantly faster than our $6 \mathrm{~m} / \mathrm{s}$ speed. At first thought, it seemed almost impossible that an albatross could soar upwind without flapping its wings with a mean velocity through the air faster than $13 \mathrm{~m} / \mathrm{s}$, significantly faster than the $7 \mathrm{~m} / \mathrm{s}$ wind. More observations of albatrosses soaring upwind and further reflection suggested that such upwind soaring is made possible by using dynamic soaring to exploit wind shear, possibly supplemented by updrafts over waves.

The term dynamic soaring refers to the extraction of energy from the gradient of wind velocity. In dynamic soaring an albatross typically climbs across the wind-shear layer while headed upwind, turns to head downwind, descends down across the wind-shear layer, and then turns upwind again (Baines, 1889; Idrac, 1925; Pennycuick, 2002). Both crossings of the wind-shear layer and the turn downwind can provide energy for sustained or energy-neutral soaring. Usually an albatross executes these two turns in an S-shaped maneuver while soaring across-wind, which is the preferred direction for albatross soaring (Alerstam et al., 1993; Wakefield, 2009).

Despite many studies of dynamic soaring there is still uncertainty about how fast a bird can soar upwind using dynamic soaring. The uncertainty is caused in part by the relatively slow upwind velocity predicted by models of dynamic soaring that use an average wind profile above a flat ocean surface. There are benefits to being able to fly fast upwind such as being able to rapidly travel to a good upwind fishing ground, being able to return and feed a hungry chick after being stuck downwind in a wind shift, and being able to keep up with a ship and scavenge discarded food scraps or discarded 
bycatch from fishing. That was probably why the albatross was shadowing our ship, which had numerous spools of wire and other mooring gear on the fantail and thus resembled a commercial fishing vessel.

The purpose of this paper is to explain how a bird can fly fast upwind by using a particular form of dynamic soaring that is somewhat different from the usual across-wind dynamic soaring maneuver. In particular a bird is able to achieve fast upwind flight by using a series of $90^{\circ}$ turns, starting with a climb across the shear layer headed upwind banked to the right (for example), then a descent across the shear layer headed across wind, and switching to a banked turn to the left toward the wind direction again. The albatross that was shadowing our research ship was doing this maneuver, starting headed across wind in a wave trough, turning upwind and climbing over the top of a wave, then turning back across wind and diving down into another wave trough.

The goal of this paper is to explore the upwind mode of travel velocity by using the Rayleigh cycle model to predict upwind travel velocities of an albatross and a roboticalbatross type UAV (Unmanned Aerial Vehicle). Part of the motivation for this study is to investigate the possible development of a robotic albatross UAV that could soar over the ocean using dynamic soaring like an albatross but much faster because of superior strength and aerodynamic performance. Possibly such a UAV could be used in environmental monitoring, search and rescue, and surveillance. In order to evaluate how effectively a UAV could survey, it is necessary to establish typical upwind and acrosswind soaring abilities. The UAV soaring was modeled on the observed soaring flight of a wandering albatross (Diomedea Exulans).

\section{Rayleigh cycle model of dynamic soaring}

Lord Rayleigh (1883) was the first to describe how a bird could use the vertical gradient of the wind velocity to obtain energy for sustained dynamic soaring, although he did not call it that. He envisioned a two-layer model with different wind speeds $(W)$ in the two layers, the speeds differing by an amount indicated by $\Delta W$. He described how a 
circling bird could gain airspeed equal to $\Delta W$ by climbing headed upwind across the boundary between layers and gaining another $\Delta W$ by descending headed downwind across the boundary, a total gain of $2 \Delta W$ in a circle (Fig. 1). If the wind gradient were sufficiently large, then it is possible that enough energy could be obtained by this maneuver to sustain soaring and even climb upwards in the wind gradient. This maneuver has become known as the Rayleigh cycle.

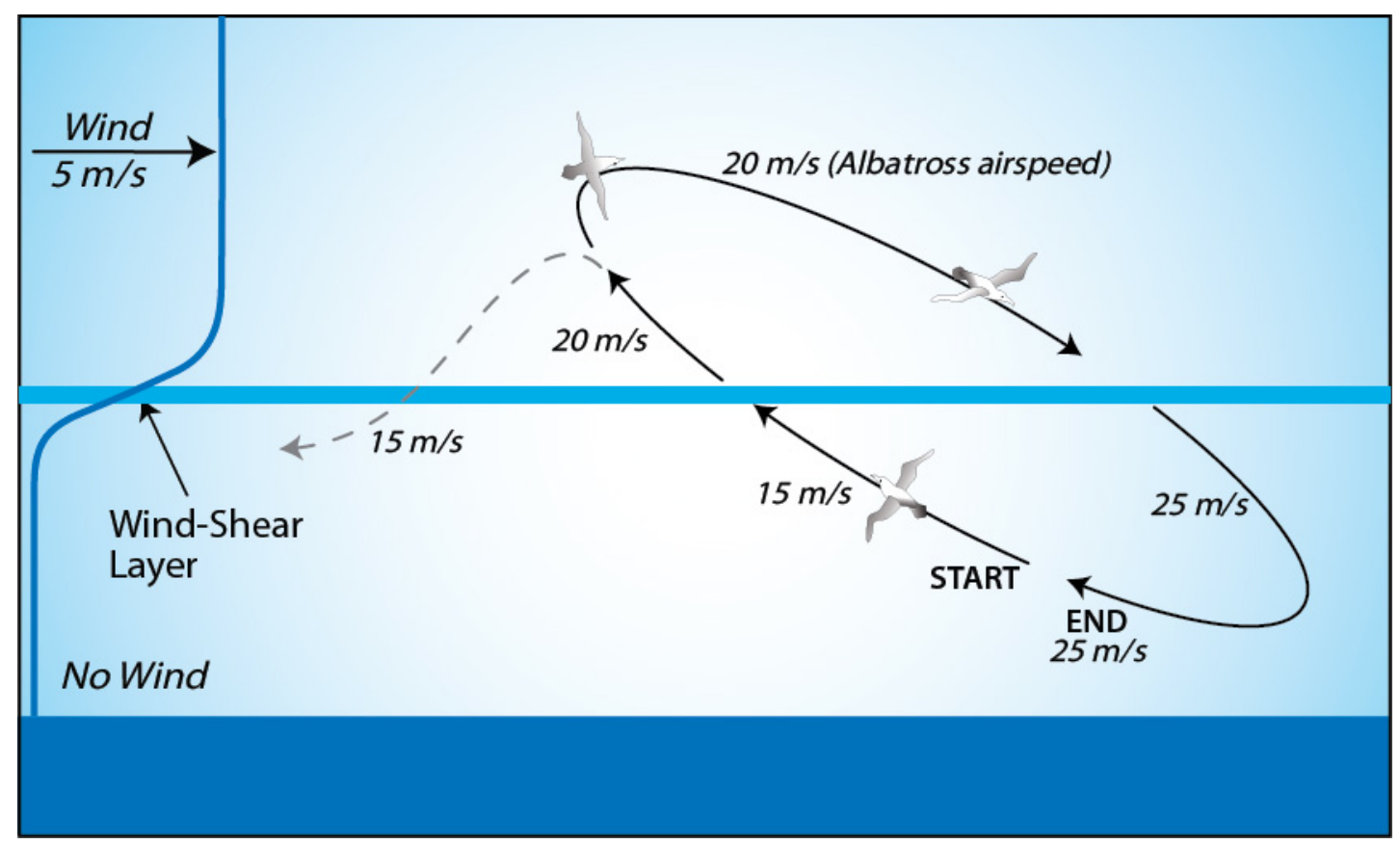

Fig. 1. Idealized example of the airspeeds of a dragless albatross dynamic soaring through a thin wind-shear layer, which is assumed to consist of an increase in wind speed from zero below the layer to $5 \mathrm{~m} / \mathrm{s}$ above. The zero speed in the lower layer represents the low wind speed located in wave troughs. This schematic is based on the written description of Rayleigh (1883) who first suggested that a bird could continuously soar in nearly-circular flight on an inclined plane that crosses a thin wind-shear layer. Starting in the lower layer with an airspeed $15 \mathrm{~m} / \mathrm{s}$ a bird climbs upwind a short distance vertically across the wind-shear layer, which increases airspeed to 20 $\mathrm{m} / \mathrm{s}$. The bird turns and flies downwind with the same airspeed of $20 \mathrm{~m} / \mathrm{s}$. During the turn, ground speed increases to $25 \mathrm{~m} / \mathrm{s}$ in a downwind direction and consists of the bird's $20 \mathrm{~m} / \mathrm{s}$ airspeed plus (tail) wind speed of $5 \mathrm{~m} / \mathrm{s}$. The bird descends downwind a short distance vertically across the wind-shear layer, which increases airspeed to $25 \mathrm{~m} / \mathrm{s}$. Flying with an airspeed of $25 \mathrm{~m} / \mathrm{s}$ the bird turns upwind. Thus, one circle through the wind-shear layer increases airspeed and groundspeed from $15 \mathrm{~m} / \mathrm{s}$ to $25 \mathrm{~m} / \mathrm{s}$ (two times the $5 \mathrm{~m} / \mathrm{s}$ wind speed increase across the wind-shear layer). By descending upwind (dashed line) the bird's airspeed would have decreased from $20 \mathrm{~m} / \mathrm{s}$ back to $15 \mathrm{~m} / \mathrm{s}$ with no net gain in airspeed. This schematic shows an oblique view of near-circular flight. 
In order to develop a (fairly) simple dynamic model of albatross dynamic soaring Richardson (2011) balanced the airspeed gain in the Rayleigh cycle with the loss of energy due to the drag of the air acting on the bird. The model is referred to as the Raleigh cycle model. Drag was modeled with a quadratic drag law in which the drag coefficient is proportional to the lift coefficient squared. Two homogenous layers were assumed, a lower layer of zero wind speed and upper layer of wind speed $W$. A thin wind-shear layer is sandwiched between the upper and lower layers. The zero wind speed in the lower layer represents the region of low wind speeds located in wave troughs. The wind in the upper layer represents the fast wind blowing above wave crests. This model agrees with the concept of an albatross gust soaring proposed by Pennyquick (2002) in which a wind gust is encountered when a bird pulls up from the low-wind region in a wave trough into the faster wind (the gust) located just above a wave crest.

The essential assumptions in the Rayleigh cycle model are that 1) the bird soars in nearly circular loops along a plane tilted upward into the wind, 2) the plane crosses the wind-shear layer at a small angle with respect to the horizon so that vertical motions can be ignored, 3) the average airspeed and average glide ratio can be used to represent flight in the circle, and 4) conservation of energy in each layer requires a balance between the sudden increase of airspeed (and kinetic energy) caused by crossing the shear layer and the gradual loss of airspeed due to drag over each half loop, resulting in energy neutral soaring (see Appendix A for a more complete description of the model.)

\section{Dynamic Soaring Maneuvers}

I have observed albatrosses to fly in three typical dynamic soaring maneuvers. The first is a circling hover mode with a bird's wings banked in the same direction similar to the basic Rayleigh cycle shown schematically in Figure 1. A minor modification of this is a figure-eight-shaped hover mode in which a bird switches the direction of its banked wings on every other crossing of the shear layer. The second maneuver is an across-wind travel mode, consisting of a series of $180^{\circ}$ turns banked successively right then left (say), while the bird is headed on an average course across the wind (Fig. 2). Using this mode, 


\section{Upwind and Across-Wind Travel Modes}

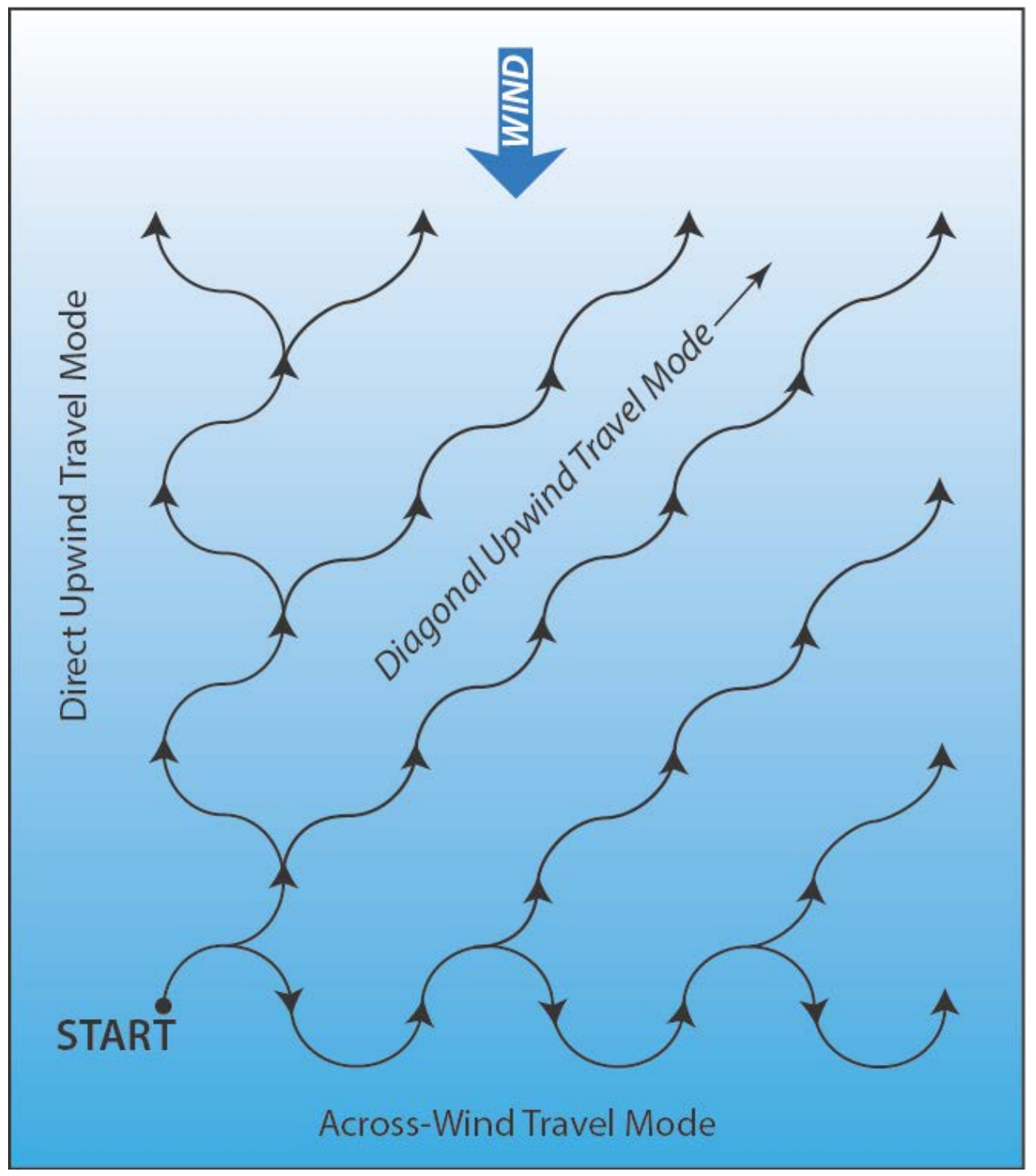

Fig. 2. Schematic examples of upwind and across-wind modes of dynamic soaring created by linking $90^{\circ}$ and $180^{\circ}$ turns into snaking flight patterns. The $16.0 \mathrm{~m} / \mathrm{s}$ cruise speed of a wandering albatross was used to calculate a $10.2 \mathrm{~m} / \mathrm{s}$ mean travel velocity through the air in the across-wind and along-wind directions and diagonal travel velocities of $14.4 \mathrm{~m} / \mathrm{s}$. Arrow heads are placed at points where the bird crosses the wind shear layer when headed either upwind or downwind and thereby gains airspeed and kinetic energy.

an albatross can soar quite fast perpendicular to the wind velocity. Tracking of albatrosses suggests that this is the usual dynamic soaring mode (Wakefield et al., 2009). It is not obvious how an albatross could use either of these techniques to soar very fast 
upwind, although some models have suggested that they can, including one based on the across-wind mode tilted in an upwind direction (Richardson, 2011). A third maneuver is an upwind travel mode in which an albatross can soar quite fast in an upwind direction as Idrac (1925) and I have observed (Fig. 2). I believe that this upwind mode better represents how an albatross actually soars upwind and is a more efficient way to gain energy from dynamic soaring than a tilted across-wind mode.

\subsection{Upwind travel mode}

In this mode a bird first climbs up across the wind-shear layer headed upwind, banks and turns $90^{\circ}$ to the right (say). The bird then descends across the wind-shear layer headed perpendicular to the wind, banks left and turns $90^{\circ}$ into the wind again. Using a series of $90^{\circ}$ turns a bird zig-zags diagonally upwind through the air at an average angle of around $45^{\circ}$ relative to the wind direction (Fig. 2). By adjusting the direction of the turns, either to the left or right after an upwind climb, a bird can effectively tack in any direction it chooses including (on average) directly upwind. To soar directly upwind the bird would execute a series of turns, first right then left, after upwind climbs (Fig. 2) resulting in a series of $180^{\circ}$ turns similar to the across-wind mode. This technique could be also used for fast down-wind soaring if a bird replaces upwind climbs across the windshear layer with downwind descents across the wind-shear layer.

The energy balance in a set of two $90^{\circ}$ turns in the diagonal upwind mode is almost exactly the same as in one $180^{\circ}$ turn. Airspeed gained in an upwind crossing of the windshear layer is reduced by drag during the two $90^{\circ}$ turns, which equal the same amount of angular turn as one $180^{\circ}$ turn. The main difference is an extra change in banking direction between $90^{\circ}$ turns. As long as the bird can change its bank angle rapidly compared to the whole maneuver then the dynamics would be unchanged from the basic circular Rayleigh cycle model. The typical observed period of time for the two $180^{\circ}$ turns of the hover mode, the across-wind mode, and the direct upwind mode is around $10 \mathrm{~s}$ for a wandering albatross, and thus the implied period of two $90^{\circ}$ turns would be around $5 \mathrm{~s}$. However, the 
albatross I observed soaring upwind executed the two $90^{\circ}$ turns in around $10 \mathrm{~s}$. (More about this below.)

\subsection{Numerical example of upwind travel mode}

The cruise air speed, $V_{c}=16 \mathrm{~m} / \mathrm{s}$, of a wandering albatross is its speed at the maximum glide ratio, which is around 21.2 in straight flight (Pennycuick, 2008). Using these values, a loop period of $10 \mathrm{~s}$, the aerodynamic equations of motion and the Rayleigh cycle model I found that the minimum wind speed in the upper layer that can support energy-neutral dynamic soaring is $3.6 \mathrm{~m} / \mathrm{s}$ (Eq. A.4). This value is in good agreement with the results of numerical simulations using the full aerodynamic equations (Lissaman, 2005, personal communication; Richardson, 2011; Sachs, 2005). The Raleigh cycle model predicts that the bird's airspeed would be $14.2 \mathrm{~m} / \mathrm{s}$ just before crossing the shear layer, would increase by $3.6 \mathrm{~m} / \mathrm{s}$ on crossing the shear layer, and would reach 17.8 $\mathrm{m} / \mathrm{s}$ just afterward. The $17.8 \mathrm{~m} / \mathrm{s}$ speed would then be reduced by drag to $14.2 \mathrm{~m} / \mathrm{s}$ by the end of a $180^{\circ}$ turn or two $90^{\circ}$ turns. The average bank angle of the maneuver would be around $46^{\circ}$ and the average acceleration acting on the bird around $1.4 \mathrm{~g}$.

The average across-wind travel velocity through the air of an albatross is equal to the diameter of a $180^{\circ}$ semi-circular turn divided by the $5 \mathrm{~s}$ to fly it. Thus the across-wind component of soaring flight would be equal to $2 V_{d} / \pi=10.2 \mathrm{~m} / \mathrm{s}$, where $V_{c}$ is the $16 \mathrm{~m} / \mathrm{s}$ cruise airspeed (Table 1, Fig. 3). In the upwind mode of flight consisting of a series of $90^{\circ}$ or $180^{\circ}$ turns, the average upwind velocity through the air would also equal $10.2 \mathrm{~m} / \mathrm{s}$ (assuming the same $5 \mathrm{~s}$ to fly $180^{\circ}$ ), as would the downwind velocity. Diagonal travel velocity at an angle of $45^{\circ}$ relative to the wind is the resultant of the across-wind and upwind values and equals $14.4 \mathrm{~m} / \mathrm{s}$, almost as fast as the bird's cruise airspeed (16 m/s). The relatively fast diagonal travel velocity is possible because the diagonal series of linked $90^{\circ}$ turns more closely approximates a straight course than does a series of linked $180^{\circ}$ turns in the across-wind or upwind directions. 


\section{Table 1}

Wandering Albatross and UAV Travel Velocities

\begin{tabular}{lcccc}
\hline & \multicolumn{2}{c}{ Wandering Albatross $\left(V_{c}=16 \mathrm{~m} / \mathrm{s}\right)$} & \multicolumn{2}{c}{ UAV $(V=9.5 \mathrm{~W})$} \\
\hline Travel Direction & $\begin{array}{c}\text { Travel Velocity } \\
\text { Through Air }(\mathrm{m} / \mathrm{s})\end{array}$ & $\begin{array}{c}\text { Travel Velocity } \\
\text { Over Ground }(\mathrm{m} / \mathrm{s})\end{array}$ & $\begin{array}{c}\text { Travel Velocity } \\
\text { Through Air }\end{array}$ & $\begin{array}{c}\text { Travel Velocity } \\
\text { Over Ground }\end{array}$ \\
\hline Upwind & 10.2 & 8.4 & $6.1 \mathrm{~W}$ & $5.6 \mathrm{~W}$ \\
Diagonal Upwind & 14.4 & $13.2\left(51^{\circ}\right)$ & $8.6 \mathrm{~W}$ & $8.3 \mathrm{~W}\left(47^{\circ}\right)$ \\
Downwind & 10.2 & 12.0 & $6.1 \mathrm{~W}$ & $6.6 \mathrm{~W}$ \\
Diagonal Downwind & 14.4 & $15.7\left(140^{\circ}\right)$ & $8.6 \mathrm{~W}$ & $9.0 \mathrm{~W}\left(137^{\circ}\right)$ \\
Across-wind & 10.2 & 10.2 & $6.1 \mathrm{~W}$ & $6.1 \mathrm{~W}$ \\
\hline
\end{tabular}

Values of travel velocity $(\mathrm{m} / \mathrm{s})$ of a wandering albatross were calculated using its cruise airspeed $\left(V_{c}\right)$ of $16 \mathrm{~m} / \mathrm{s}$ at the maximum lift/drag ratio of 21.2, a loop period of $10 \mathrm{~s}$, the Rayleigh cycle model, a wind speed of $3.6 \mathrm{~m} / \mathrm{s}$ (the minimum for dynamic soaring), and a combination of upwind and across-wind soaring modes as shown in Fig. 2. The average bank angle is $46^{\circ}$ and average acceleration is $1.4 \mathrm{~g}$. The UAV's maximum airspeed was calculated with the Rayleigh cycle model to be $9.5 W$, where $W$ is the wind speed in the upper layer (Eq. A10, see text). This relation, UAV airspeed $=9.5 \mathrm{~W}$, is a good approximation for wind speeds greater than around 5 $\mathrm{m} / \mathrm{s}$. UAV travel velocities were calculated using this airspeed and a combination of soaring modes as shown in Fig. 2. In order to obtain the travel velocity over the ground, values of travel velocity through the air were corrected for leeway, estimated to be one half the wind speed of the upper layer. Values in parentheses are the angles of travel velocity relative to the wind direction, which was assumed to be from zero degrees.

\subsection{Leeway}

In all three modes of dynamic soaring maneuvers there is downwind leeway caused by the portion of flight in the upper wind layer. A bird spends approximately half of its time in each layer and thus the average leeway in a maneuver equals around one half of the wind velocity of the upper layer. This leeway value needs to be applied to the bird's mean velocity through the air in order to obtain the bird's travel velocity over the ground. In principle, a bird could extend the upwind flight legs to compensate for leeway. This would make the hover mode more stationary and make the across-wind travel mode perpendicular to the wind. It would require gaining a bit more energy from the windshear layer and a slightly faster wind than without compensating for leeway.

In the upwind mode, the upwind velocity of $10.2 \mathrm{~m} / \mathrm{s}$ would be countered by leeway of $1.8 \mathrm{~m} / \mathrm{s}$ (half the wind speed in the upper layer) resulting in an upwind travel velocity 
over the ground of $8.4 \mathrm{~m} / \mathrm{s}$ (Table 1, Fig. 3). Correcting for leeway results in a diagonal upwind travel velocity of $13.2 \mathrm{~m} / \mathrm{s}$ at a direction of around $51^{\circ}$ relative to the wind. In a 7 $\mathrm{m} / \mathrm{s}$ wind the upwind travel velocity would be $6.7 \mathrm{~m} / \mathrm{s}$, enough to follow our ship but not enough to rapidly catch up to it from astern.

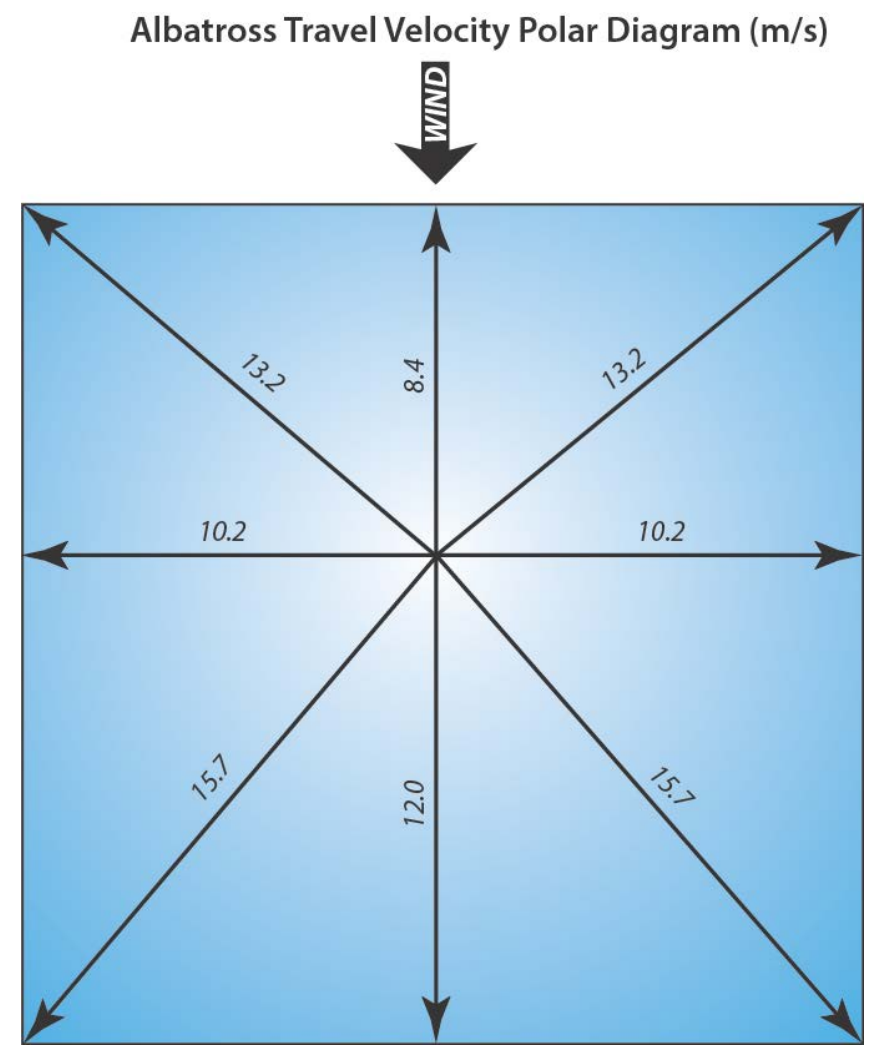

Fig. 3. Travel velocity polar diagram of a wandering albatross created using upwind and acrosswind dynamic soaring modes (see Fig. 2). The square shape is a result of the equal travel velocities through the air in the along-wind and across-wind directions. Values of mean travel velocities over the ground have been added to characteristic flight directions. The diagram was created using the cruise airspeed $(16.0 \mathrm{~m} / \mathrm{s})$ of the bird and the minimum wind speed $(3.6 \mathrm{~m} / \mathrm{s})$ necessary for continuous dynamic soaring. Values were corrected for leeway $(1.8 \mathrm{~m} / \mathrm{s})$, which was estimated to be one half of the wind speed, based on assuming that the bird spends equal time in the upper and lower layers.

The diagonal travel velocity over the ground is significantly faster than either the direct upwind or across-wind travel velocities. This suggests that diagonal flight would be the fastest way to travel over the ocean, especially downwind diagonal flight at 15.7 
$\mathrm{m} / \mathrm{s}$, which is very close to the bird's $16 \mathrm{~m} / \mathrm{s}$ cruise velocity through the air. An albatross could choose a diagonal flight mode in order to make the fastest passage to feeding grounds or a fast return. The implication is that the fastest way an albatross could search a particular region for food would be to use a diagonal flight pattern.

\subsection{Across-wind descent}

An important detail should be mentioned about the descent across the wind-shear layer when headed perpendicular to the wind. As a bird soars in the upper layer on a heading of $90^{\circ}$ with respect to the wind direction (considered to come from zero degrees), for example, the wind causes a downwind leeway to the bird's right at the wind speed $(3.6 \mathrm{~m} / \mathrm{s})$ so that the direction of flight over the ground is toward $103^{\circ}$. When descending on a $90^{\circ}$ heading across the wind-shear layer, the apparent wind encountered by the bird shifts to the right around $13^{\circ}$ due to the leeway component. At this point the bird could quickly yaw to the right to head into the apparent wind direction then bank left to start the “90" " upwind turn, which would be approximately $103^{\circ}$. In order to retain the upwind travel mode Raleigh cycle of approximately two $90^{\circ}$ turns that sum to $180^{\circ}$ a bird could descend across the wind shear layer when headed toward $83.5^{\circ}$ (after a $83.5^{\circ}$ turn), then quickly yaw right toward $96.5^{\circ}$ (the direction of the bird's velocity over the ground), then bank left and turn $96.5^{\circ}$ into the wind. The sum of these two turns is $180^{\circ}$. Presumably, a bird would know how to maximize its upwind velocity by optimally adjusting the turns somewhat like the maneuver envisioned here.

\subsection{Dynamic soaring in higher wind speeds}

In principle, albatrosses can use winds faster than the minimum $(3.6 \mathrm{~m} / \mathrm{s})$ required for dynamic soaring to gain more energy from the wind and fly faster than the cruise airspeed of $16 \mathrm{~m} / \mathrm{s}$. They probably actually do this at least for moderate increases of airspeed. The albatross I saw using the upwind soaring mode in a wind of $7 \mathrm{~m} / \mathrm{s}$ was completing the two $90^{\circ}$ turns in around $10 \mathrm{~s}$. Using these values the Rayleigh cycle 
model predicts that the bird could soar with an average airspeed of around $24 \mathrm{~m} / \mathrm{s}$, an average bank angle of $38^{\circ}$, and average acceleration of around $1.3 \mathrm{~g}$, which seems reasonable. This airspeed corresponds to upwind and across-wind travel velocities through the air of $15.6 \mathrm{~m} / \mathrm{s}$. Correcting for leeway gives an upwind travel velocity over the ground of $12.1 \mathrm{~m} / \mathrm{s}$. This is almost twice as fast as the upwind travel velocity (6.7 $\mathrm{m} / \mathrm{s}$ ) with a $16 \mathrm{~m} / \mathrm{s}$ airspeed and $7 \mathrm{~m} / \mathrm{s}$ wind. This result suggests that the albatross I observed had more than enough upwind travel velocity to catch up with our ship (as observed). The implication is that as long as the acceleration of an albatross can be kept to a reasonable level below the maximum strength of the bird's wings, the bird could increase its upwind and across-wind travel velocity with winds faster than $3.6 \mathrm{~m} / \mathrm{s}$. The Rayleigh cycle model indicates that an albatross could increase its airspeed as wind speed increases and, by increasing the period of the maneuver, maintain a constant average

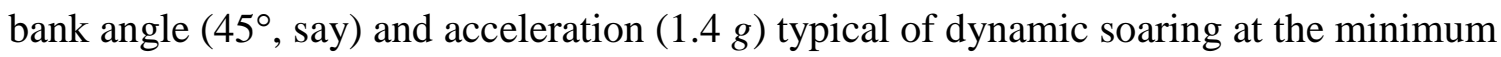

wind speed $(3.6 \mathrm{~m} / \mathrm{s})$. This suggests that the travel velocities in Table 1 and in Figure 3 could underestimate real albatross travel velocities in wind speeds faster than $3.6 \mathrm{~m} / \mathrm{s}$. However, there is some contrary evidence against faster airspeeds in faster winds as discussed below.

\subsection{Discussion of albatross airspeeds faster than $16 \mathrm{~m} / \mathrm{s}$}

Wakefield et al. (2009) found a linear relationship between the ground speed of albatrosses and the wind-speed component in the direction of flight. For example, the ground speed of a wandering albatross was found to equal an average $10 \mathrm{~m} / \mathrm{s}$ plus 0.4 times the wind component at $5 \mathrm{~m}$ height in the direction of flight (their Table 1). The Rayleigh cycle model predicts a similar $10 \mathrm{~m} / \mathrm{s}$ travel velocity through the air for a wind speed of $3.6 \mathrm{~m} / \mathrm{s}$, as described above. The observed speeds used by Wakefield et al. suggest that albatrosses generally fly with an average $10 \mathrm{~m} / \mathrm{s}$ travel velocity through the air even in relatively fast winds of 6-9 m/s and large wind shears. The implication is that the birds can control the amount of energy in dynamic soaring in order to maintain a nearly constant average airspeed. Some possible ways a bird could limit energy gain and airspeed in faster winds would be to climb and descend obliquely across the wind-shear 
layer, to soar in the weaker shear located higher up in the wind-shear layer, and to decrease the frequency of shear-layer crossings.

The average $10 \mathrm{~m} / \mathrm{s}$ travel velocity through the air found by Wakefield et al. appears to contradict the faster upwind travel velocity through the air $(15.6 \mathrm{~m} / \mathrm{s})$ and faster airspeed ( $24 \mathrm{~m} / \mathrm{s}$ ) calculated above using a $7 \mathrm{~m} / \mathrm{s}$ wind speed. There are at least two possible explanations of this discord. The first is that albatrosses usually prefer the across-wind travel mode soaring at a travel velocity of $10 \mathrm{~m} / \mathrm{s}$ because that is easy for them. Therefore, the preponderance of observations used by Wakefield et al. are probably from the common across-wind flight with few observations from fast upwind flight. Secondly, significant scatter can be seen in the plot (their Fig. 2, top panel) showing the correlation between the ground speed of wandering albatrosses measured with GPS and the wind velocity component in the direction of flight. In particular, there is a cluster of around 6 observations of ground speeds of 10-13 m/s matching a head wind speed component of $7 \mathrm{~m} / \mathrm{s}$, corroborating my upwind flight observations and the Rayleigh model predictions. These GPS data indicate that at times albatrosses are quite capable of exploiting moderately fast wind speeds in order to soar significantly faster than the typical cruise airspeed and in an upwind direction.

The albatross tracking data used by Wakefield et al. are fairly infrequent positions with no information about the fine-scale details of the dynamic soaring flight such as high-resolution trajectories over the ground and the times to fly the various maneuvers. This kind of information is needed in order to be able to further evaluate how albatrosses use the wind to gain energy in soaring over the ocean and how fast they can fly using the different travel modes. A few albatrosses have now been tracked with higher temporal resolution GPS positions and flight details are starting to be published (Sachs et al., 2013; Weimerskirch et al., 2002). More of these high temporal resolution data including air speed measurements are needed to reveal how an albatross uses dynamic soaring and to accurately model the soaring techniques.

\section{Possible upwind dynamic soaring of a robotic albatross UAV}


Recent observations of fast radio-controlled gliders suggest that they might form the basis of a robotic albatross UAV (Unmanned Aerial Vehicle) that could use dynamic soaring to fly over the ocean much faster than a real albatross. The goal of this part of the paper is to explore this concept using the observed albatross soaring modes (Fig. 4).

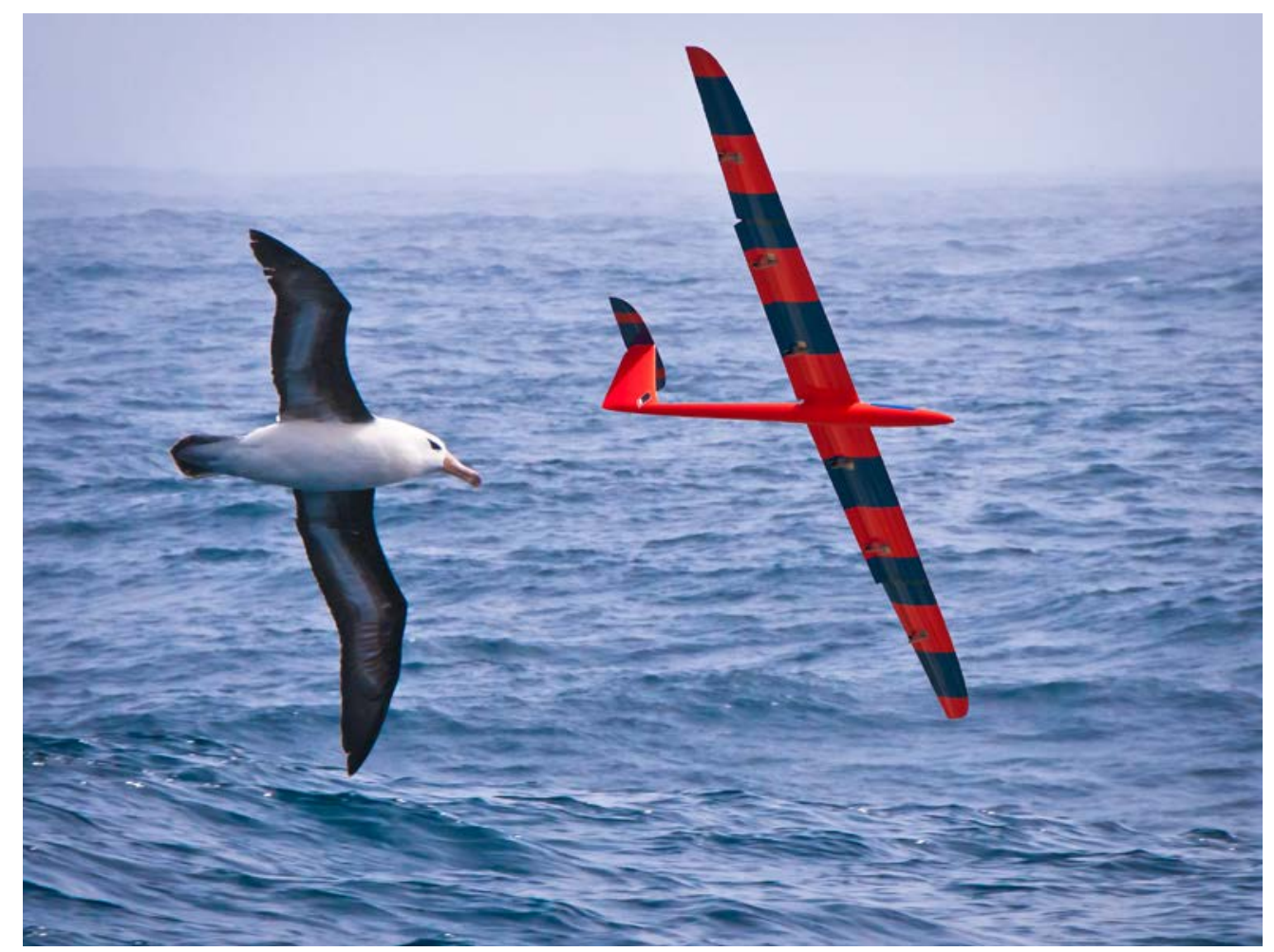

Fig. 4. Conceptual illustration of a robotic albatross UAV dynamic soaring over the ocean. A photo of a Kinetic 100DP glider flown by Spencer Lisenby at Weldon Hill, California was superimposed onto a photo of a black-browed albatross soaring over the Southern Ocean. Photos by Phil Richardson.

\subsection{Observations of fast dynamic soaring radio-controlled gliders}

Pilots of radio-controlled gliders have recently used dynamic soaring to exploit winds blowing over mountain ridges to fly gliders at astonishingly fast speeds in nearly circular loops similar to the hover mode. In 2012 I observed gliders being flown at speeds up to around 200 m/s at Weldon Hill near Lake Isabella, California in wind speed gusts of 20- 
$30 \mathrm{~m} / \mathrm{s}$ near the top of the ridge. The present unofficial world record is a peak speed of 223 m/s (498 mph) held by Spencer Lisenby flying a Kinetic 100 DP glider with a 2.5 m wingspan, similar to that of some albatrosses (http://www.rcspeeds.com/aircraftspeeds.aspx). One almost has to see and hear these extremely fast gliders to believe how fast they can go and to appreciate their extreme performance. Anecdotal information suggests that peak glider speeds as measured by radar guns are roughly equal to 10 times the airspeed blowing over the crest of the ridge (Lisenby, personal communication).

\subsection{Model simulations of fast radio-controlled gliders and possible UAVs}

In order to better understand the dynamic soaring of these gliders I used the Raleigh cycle model to simulate their flight. The Rayleigh cycle model is appropriate for this because the low-wind region downwind of the mountain ridges and the fast wind speeds located just above the crest of the ridge match the two model layers. A maximum lift to drag ratio of 30/1 at a cruise speed of 25 m/s was estimated for a Kinetic 100 DP glider (Lisenby, personal communication).

Using these values the Rayleigh cycle model predicts that the maximum possible airspeed is equal to around 9.5 times the wind speed in the upper layer for wind speeds greater than around $5 \mathrm{~m} / \mathrm{s}$ (Eq. A10). The 9.5 factor agrees quite closely with the anecdotal factor of around 10. These fast gliders need to be very strong since peak accelerations estimated from the Rayleigh cycle model and some accelerometer observations (Chris Bosley, personal communication) are around $100 \mathrm{~g}$ 's. The gliders are highly maneuverable as demonstrated by successful dynamic soaring at high speeds close to the ground in gusty winds, by numerous remarkable acrobatic tricks, and by safely landing on top of a very windy gusty ridge. (See Richardson, 2012 for more discussion about high-speed dynamic soaring gliders.)

\subsection{Upwind travel velocities of a robotic albatross UAV}


The maximum possible upwind travel velocity of a UAV was modeled with the airspeed calculated using the Rayleigh cycle model optimized for fast flight and the upwind flight mode shown in Fig. 2. Values of maximum travel velocity through the air as a function of wind speed $(W)$ are given in Table 1 , and maximum possible upwind travel velocities over the ground as a function of wind speed given in Figure 5. The range of possible upwind velocities plotted against wind speed is indicated in Figure 5 by darker blue shading. An important result is the large region of possible upwind travel velocities and wind speeds using a dynamic soaring UAV.

\section{UAV Upwind Travel Velocities}

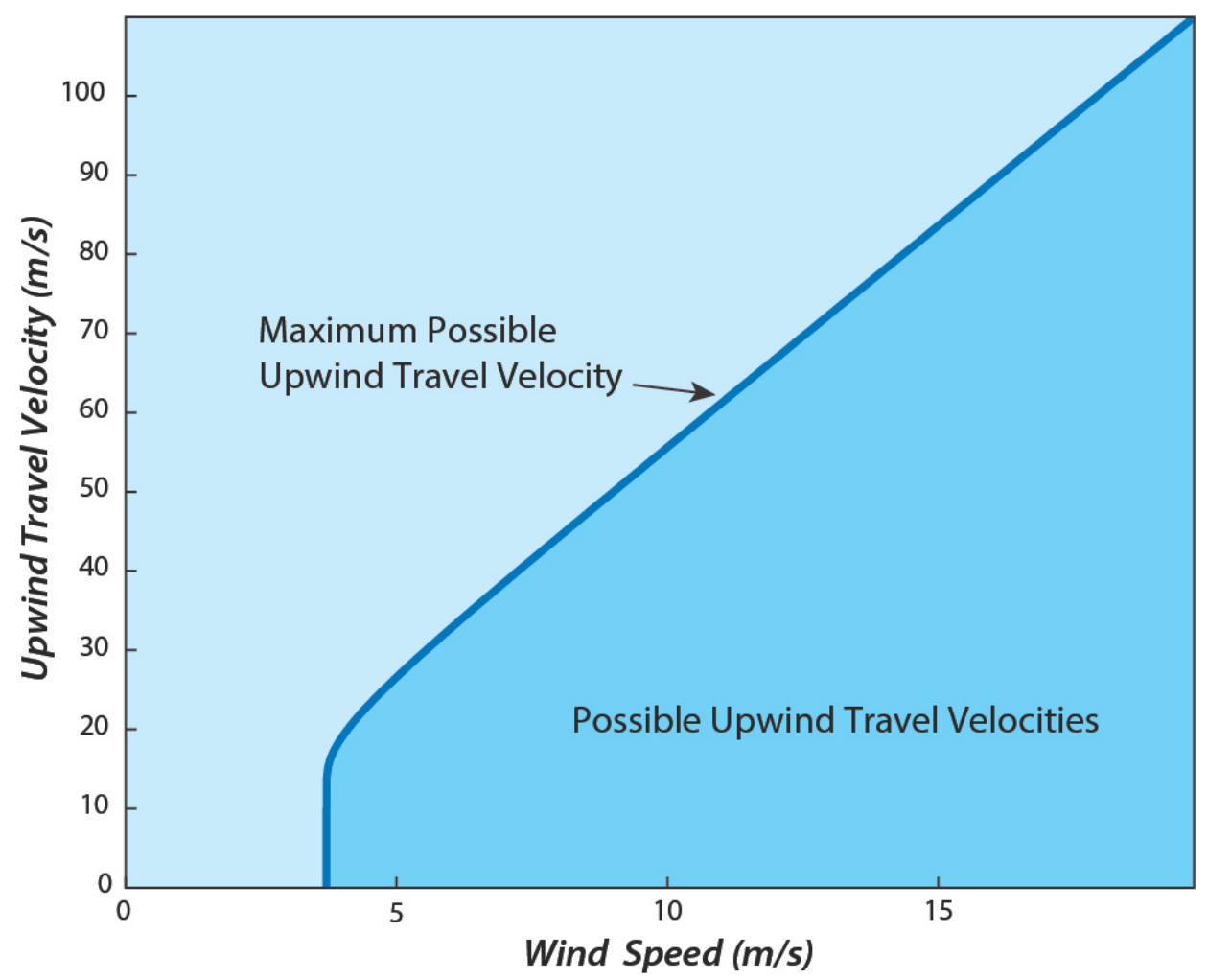

Fig. 5. Envelope of maximum possible upwind UAV travel velocities over the ground (corrected for leeway) plotted as a function of wind speed. Velocities were calculated using the upwind mode of the Rayleigh cycle model and by assuming a maximum lift/drag ratio of 30/1 at a cruise speed of $25 \mathrm{~m} / \mathrm{s}$ (similar to a Kinetic $100 \mathrm{DP}$ glider). The darker blue area indicates all possible upwind UAV travel velocities as a function of wind speed $(W)$. The UAV was assumed to be able to obtain the correct amount of energy for each wind speed in order to soar upwind at slower airspeeds than the maximum possible. 
As a numerical example, a wind speed of $10 \mathrm{~m} / \mathrm{s}$ could in principle provide sufficient energy to soar at airspeeds up to $95 \mathrm{~m} / \mathrm{s}$ (Eq. A.10). The resulting maximum upwind travel velocity through the air would be $61 \mathrm{~m} / \mathrm{s}$, and the maximum diagonal travel velocity would be $86 \mathrm{~m} / \mathrm{s}$ (Table 1). Correcting for leeway gives a maximum upwind velocity over the ground of $56 \mathrm{~m} / \mathrm{s}$ and a maximum upwind diagonal velocity of $83 \mathrm{~m} / \mathrm{s}$. The values of the maximum possible travel velocities are illustrated in a velocity polar diagram for a UAV (Fig. 6).

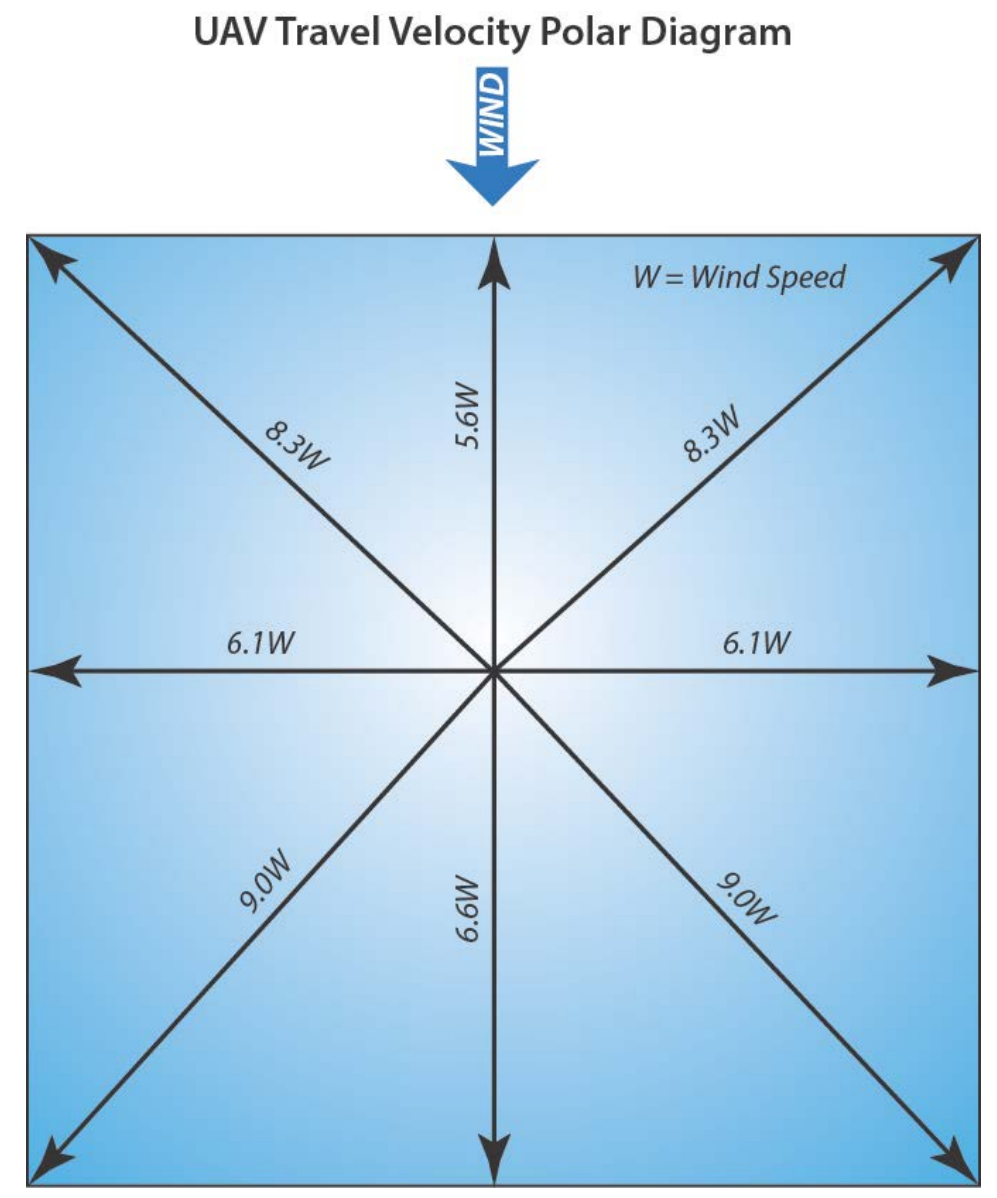

Fig. 6. Travel velocity polar diagram of a robotic albatross UAV. The square shape is a result of the equal travel velocities through the air in the along-wind and across-wind directions. The diagram was created by assuming a characteristic lift/drag ratio of 30/1, a cruise velocity of 25 $\mathrm{m} / \mathrm{s}$ (similar to a Kinetic 100 DP glider), and by calculating airspeeds based on the Raleigh cycle model optimized to give the maximum possible airspeed for a given wind speed. Travel velocities have been corrected for leeway and represent velocities over the ground. Specific given values of travel velocity represent the linear relation between travel velocity over the ground and wind speed $(W)$ for wind speeds over around $5 \mathrm{~m} / \mathrm{s}$ (see text). For example, a wind speed of $10 \mathrm{~m} / \mathrm{s}$ 
results in maximum possible travel velocities over the ground of $56 \mathrm{~m} / \mathrm{s}$ upwind, $83 \mathrm{~m} / \mathrm{s}$ diagonally upwind, and $61 \mathrm{~m} / \mathrm{s}$ across-wind.

\subsection{Possible UAV Survey mode}

A main result of these calculations is to show that in principle very fast upwind UAV travel velocities are possible over the ocean when using the energy extracted from the wind in dynamic soaring. In a $10 \mathrm{~m} / \mathrm{s}$ wind the maximum diagonal upwind travel velocity over the ground is $83 \mathrm{~m} / \mathrm{s}$, over six times faster than that of an albatross flying with a travel velocity of $16 \mathrm{~m} / \mathrm{s}$. These results indicate that the fastest way to survey or search a particular part of the ocean using a dynamic soaring UAV would be along diagonal lines (Fig. 7).

\section{Possible UAV Survey Pattern}

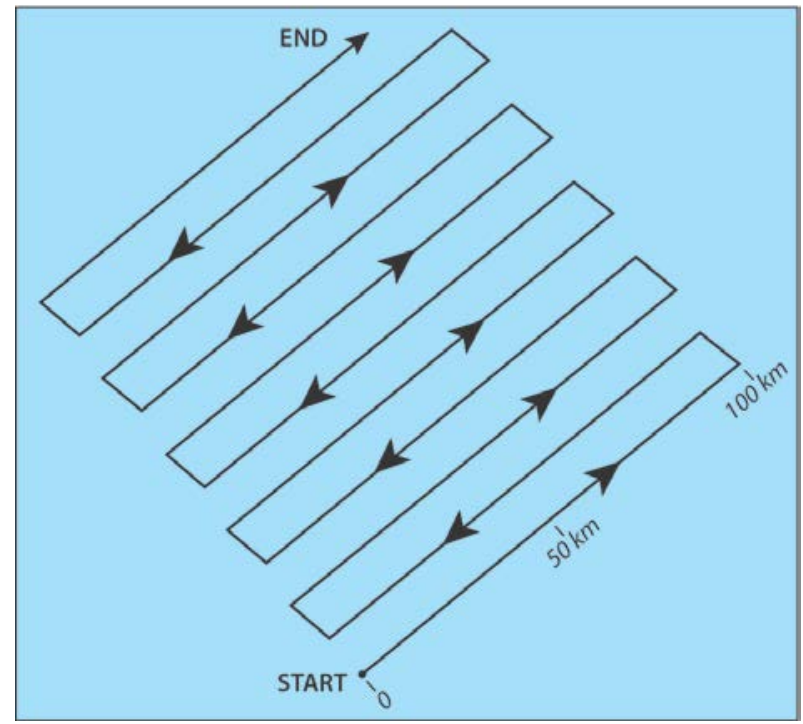

Fig. 7. Schematic diagram showing a possible UAV survey mode using a combination of upwind and downwind modes of the Rayleigh cycle consisting of diagonal trajectories with respect to the wind direction (Fig. 2). Diagonal velocities are the fastest possible travel velocities over the ocean using the upwind (and downwind) mode. They enable rapid surveying of an area for any given wind direction given sufficient wind for dynamic soaring. For example, in a wind speed of $10 \mathrm{~m} / \mathrm{s}$ the average maximum possible diagonal velocities are $86 \mathrm{~m} / \mathrm{s}$ (Fig. 6). 
A hypothetical survey mode using diagonal lines is shown in Figure 7. In principle a UAV could complete such a survey more than 14 times faster than could a $6 \mathrm{~m} / \mathrm{s}$ ship. This suggests that UAVs could provide rapid measurements over the ocean and supplement much slower insitu sampling by ship. In addition UAVs could be used in combination with surface drifters to follow oil spills or other pollutants in the surface layer and for search and rescue operations.

\subsection{Previous numerical simulations of the upwind travel mode of UAVs}

Deittert et al. (2009) modeled a UAV dynamic soaring through an exponential wind profile over a flat ocean (no waves). Only modest upwind travel velocities were obtained reaching around 2-6 m/s in wind speeds of 8 to $20 \mathrm{~m} / \mathrm{s}$ referenced to a height of $20 \mathrm{~m}$. These upwind velocities are much slower than the maximum upwind travel velocities of $\sim 45-112 \mathrm{~m} / \mathrm{s}$ predicted using the Rayleigh cycle model and the same wind speeds. Two major differences between models explain the very different predictions. The first is that most ( 70\%) of the increase of wind speed above the ocean in the $20 \mathrm{~m}$ exponential wind layer occurs in the first $1.5 \mathrm{~m}$ above the surface. Thus most of the increase of wind speed in the profile was missed by the UAV. The second major difference is that the UAV remained in the faster contrary winds above the surface and thus had a large leeway. Deittert et al. show a detailed plot of the direct upwind snaking mode with heights flown between approximately 1-25 $\mathrm{m}$ in a wind profile with airspeed of $12 \mathrm{~m} / \mathrm{s}$ at $20 \mathrm{~m}$. The estimated increase of wind speed $(\Delta W)$ encountered by the UAV in this example is around $4 \mathrm{~m} / \mathrm{s}$, the maximum upwind travel velocity is around $6 \mathrm{~m} / \mathrm{s}$, and the leeway is around $11 \mathrm{~m} / \mathrm{s}$. The Rayleigh cycle model predicts a nearly-equal upwind travel velocity through the air as the Deittert et al. model when using the same $\Delta W$, cruise airspeed, and lift/drag ratio. The main difference between model predictions is the much larger leeway $\sim 11 \mathrm{~m} / \mathrm{s}$ (Deittert et al.) as opposed to the $2 \mathrm{~m} / \mathrm{s}$ predicted by the Rayleigh cycle model.

Barnes (2004) simulated a direct upwind snaking mode using an exponential wind profile over a flat ocean with a wind speed of $7 \mathrm{~m} / \mathrm{s}$ at a height of $20 \mathrm{~m}$. His predicted 
UAV upwind travel velocity was $3.6 \mathrm{~m} / \mathrm{s}$, also much slower than the predictions of the Rayleigh cycle model for the same reasons as mentioned above. Bower (2012) modeled dynamic soaring over a flat ocean using linear and exponential wind profiles. With a 12 $\mathrm{m} / \mathrm{s}$ wind at a $10 \mathrm{~m}$ reference height his UAV could not travel upwind due to a smaller maximum lift/drag ratio ( 20) and a large leeway.

The relatively slow upwind travel velocities obtained by Barnes (2004) and Deittert et al. (2009) emphasize that in order to fly fast upwind it is important to exploit the full wind-shear layer located just above wave crests and to remain in the slow winds located downwind of wave crests and shielded from the faster winds for part of the flight. The Rayleigh cycle model includes both of these features-flight in the wave trough and climbs upwind across the main wind-shear layer-similar to the gust-soaring technique proposed by Pennycuick (2008).

Numerical simulations like those mentioned above could be made more relevant to soaring over the real ocean by incorporating the dynamic soaring of a UAV in a model that resolves wind-wave interactions and features like lee eddies and detached shear layers, which albatrosses use for gust soaring. It seems probable that when these features are incorporated into a simulation, a model UAV could fly closer to the speeds found using the Rayleigh cycle model. Such simulations could also reveal information about optimal flight over waves. On the other had, the slower upwind travel velocities found in simulations over a flat ocean could be more realistic in practice if UAV gust soaring turns out to be much less efficient than predicted by the Rayleigh cycle. Field tests should be able to provide information about how well a real UAV could soar over the ocean.

\subsection{Dynamic soaring of a UAV over the real ocean}

The results of the Rayleigh cycle simulations indicate that much faster UAV upwind velocities are possible than those of an albatross. How much faster needs to be determined from further studies. The modeled fast upwind UAV travel velocities are based on the observed albatross dynamic soaring flight patterns. A fundamental question 
is how well can a UAV mimic albatross maneuvers and also increase the frequency of shear-layer crossings in order to gain sufficient energy for fast travel velocities?

In the low-level part of a swoop in a wave trough, an albatross flies very close to the ocean surface, close enough so that the bird's wing tip often grazes the surface. This allows the bird to descend into a lee eddy located in a wave trough and be shielded from the full force of the wind. Grazing the water surface with wing tip feathers is not a problem for an albatross, but touching the wing of a UAV could cause a crash. Thus, a UAV must maintain a safe gliding distance above the ocean surface. But, to fully exploit gust soaring a UAV must be able to descend below the wind-shear layer into a wave trough, and this could be compromised if the minimum safe flying height above the ocean surface were greater than the wave height. Therefore, it seems likely that increasing a UAV's height above the ocean for safety could lead to a reduced amount of energy gained from the available wind shear, especially with low-amplitude waves. As demonstrated by the numerical simulations of dynamic soaring over a flat ocean, including a safe minimum soaring height limits the energy gain, airspeed, and upwind travel velocity of a UAV.

Clearly there is a wide range of possible UAV upwind travel velocities using dynamic soaring as indicated in Figure 5. It is necessary to establish values optimized for flight over real ocean waves in various wind conditions and to refine such a figure. To do so it would be beneficial to have experienced pilots of RC gliders take various highperformance waterproof gliders to sea and experiment with field trials in order to measure how fast dynamic soaring could be accomplished in realistic winds and waves. In such trials it would be helpful to have the gliders instrumented to measure high temporal resolution series of positions, orientations, accelerations and velocities through the air as well as observations of the wind and waves.

\subsection{Design of a robotic albatross UAV}


The UAV discussed here was modeled on the kinetic 100 DP high-performance glider, which is optimized for fast dynamic soaring using fast winds blowing over mountain ridges and not optimized for slower winds blowing over waves like albatrosses often exploit. An appropriate robotic albatross UAV should probably be optimized for slower winds, which can often limit dynamic soaring. In slow winds albatrosses often use a flapgliding technique to supplement dynamic soaring, and when the wind dies altogether the birds typically land on the water. A useful UAV would also need auxiliary power for slow winds and the ability to land on water and take off again. Other important developments are sensors to measure winds and waves from a UAV and an autopilot that could implement dynamic soaring using these measurements.

\section{Summary of results}

An upwind dynamic soaring mode was modeled using a series of $90^{\circ}$ turns linking upwind climbs across the wind-shear layer and across-wind descents across the windshear layer (Fig. 2). The upwind mode can be used to soar downwind by descending downwind across the wind-shear layer instead of climbing upwind across it. A series of $90^{\circ}$ turns can be combined to soar in any direction including directly upwind and downwind somewhat similar to the courses made good by a sailboat tacking in the wind (Fig. 2).

An albatross travel velocity polar diagram was constructed by combining the upwind and across-wind travel modes using the minimum wind $(3.6 \mathrm{~m} / \mathrm{s})$ for energy-neutral dynamic soaring (Fig. 3). The upwind component of travel velocity over the ground is 8.4 $\mathrm{m} / \mathrm{s}$, considerably larger than the wind speed $(3.6 \mathrm{~m} / \mathrm{s})$. The fastest travel velocity over the ground in the upwind half of the diagram is $13.2 \mathrm{~m} / \mathrm{s}$ along diagonals heading in a direction of around $51^{\circ}$ relative to the wind direction. The upwind travel velocity of an albatross soaring in a wind of $7 \mathrm{~m} / \mathrm{s}$ was calculated to be around $12 \mathrm{~m} / \mathrm{s}$, more than enough to explain how an albatross was able to catch up to our $(6 \mathrm{~m} / \mathrm{s})$ ship steaming upwind. 
The concept of a fast dynamic soaring robotic albatross UAV was explored based on the characteristics of high speed radio-controlled gliders, which have exploited dynamic soaring to reach speeds up to $220 \mathrm{~m} / \mathrm{s}$. Maximum possible airspeeds of a such a UAV were simulated by optimizing the Rayleigh cycle model for maximum airspeed. Although such fast airspeeds might not be achievable in practice by a UAV soaring over the ocean for reasons mentioned above, the speeds and resulting travel velocities give an indication of the maximum possible using the Rayleigh cycle. The wide range of possible UAV upwind travel velocities as a function of wind speed was shown in Figure 5.

A polar diagram of UAV travel velocities over the ground as a function of wind speed is given in Fig. 6. The maximum possible upwind travel velocity in a $10 \mathrm{~m} / \mathrm{s}$ wind was found to be $56 \mathrm{~m} / \mathrm{s}$ and the maximum diagonal upwind velocity is $83 \mathrm{~m} / \mathrm{s}$. These very fast speeds demonstrate the power of using dynamic soaring and suggest that in principle UAV travel velocities over the ocean could be many times faster than that of albatrosses. Even if the achievable UAV travel velocities over the real ocean turn out to be only half of the predicted values, they would still be much faster than those of an albatross. Figure 5 also indicates that a dynamic soaring UAV could travel in any direction over the ocean and not be limited by the small upwind travel velocities predicted by models that include a flat ocean. The fast diagonal travel velocities suggest that a rapid search or survey mode over the ocean might consist of a series of parallel diagonal tracks relative to the wind direction offset from each other as illustrated in Fig. 7.

\section{Conclusions and recommendations}

The results of this study suggest that a robotic albatross UAV could soar much faster than an albatross and be useful for many applications. In order to evaluate how effectively an AUV could soar over the real ocean in different wind and wave condition several studies could to be undertaken. First, numerical simulations could be made of the interaction of winds and waves, of the resulting structures in the wind field including updrafts and detached shear layers, and of the optimal dynamic soaring patterns using the wind field over waves. Second, albatrosses could be instrumented to better measure their 
dynamic soaring techniques in various winds and waves. Specifically, high temporal resolution time series could be obtained of albatrosses' positions, velocities, orientations, accelerations, and airspeeds, and these related to insitu observations of winds and waves. Third, expert pilots of radio-controlled gliders who are experienced in fast dynamic soaring could conduct field tests in order to evaluate fast dynamic soaring over the ocean with high-performance waterproof gliders and to establish safe minimum soaring heights above the ocean surface. These gliders should be instrumented as would be the albatrosses mentioned above. Using the results of the simulations and measurements of albatross and radio-controlled glider flight, a dynamic soaring autopilot could be developed. Finally, a prototype waterproof, instrumented, dynamic soaring UAV with backup auxiliary power could be constructed and tested over the ocean.

\section{Acknowledgements}

This paper was stimulated by the observed flight of albatrosses and radio-controlled gliders and by discussions of dynamic soaring with Peter Lissaman and Colin Taylor. Financial support was provided by the F. Livermore Trust and Woods Hole Oceanographic Institution emeritus funds. Paul Oberlander prepared the figures. 


\section{Appendix A}

\section{A.1. Nomenclature}

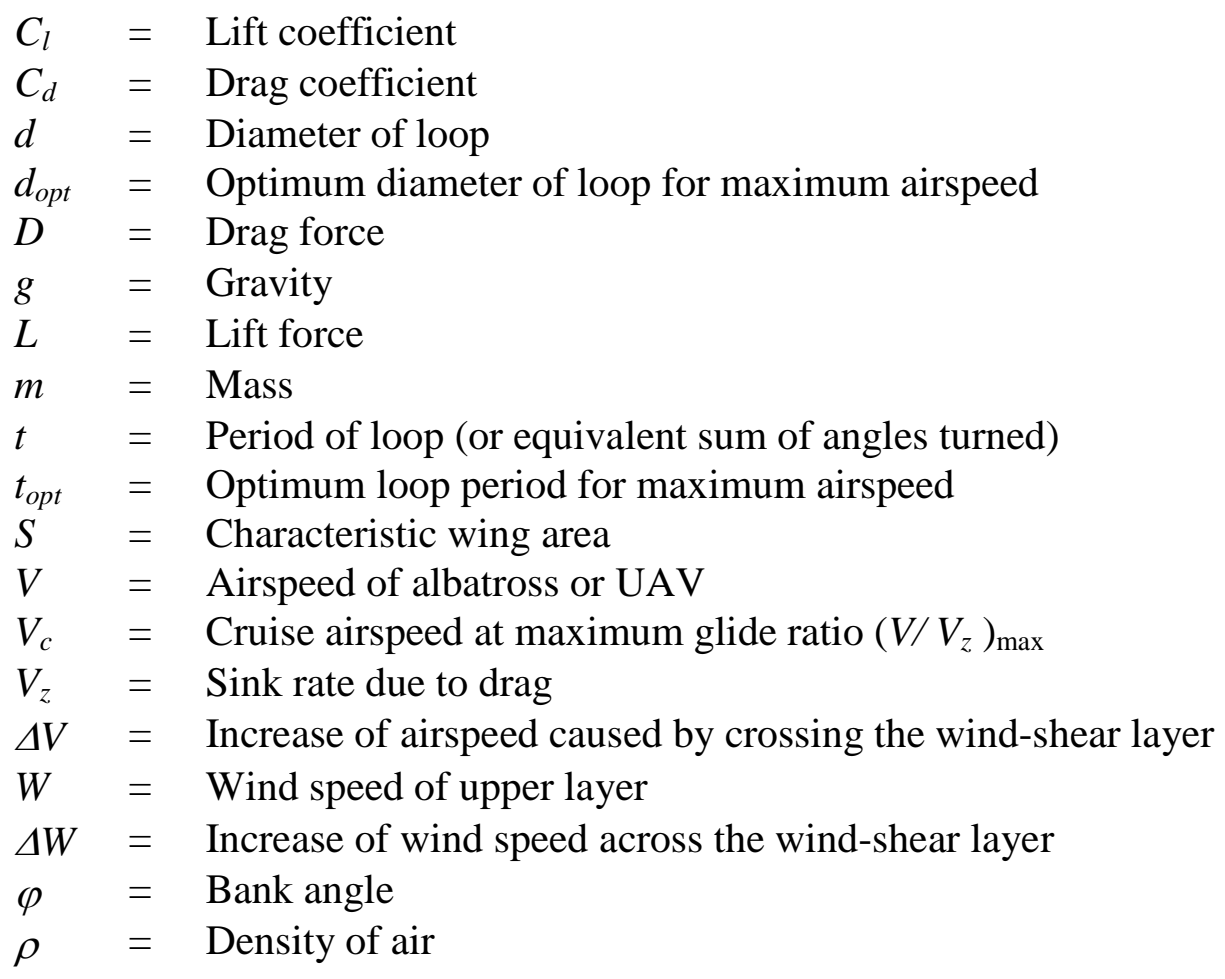

\section{A.2. Rayleigh cycle model}

In the Rayleigh cycle model the sudden gain in airspeed of a glider climbing across the wind-shear layer headed into the wind is $\Delta V$. This $\Delta V$ is assumed to equal the vertical increase of wind speed $(\Delta W)$ across the layer and also the wind speed $W$ of the upper layer, assuming zero wind speed in the lower layer. A similar increase of airspeed is obtained by a glider descending across the wind-shear layer headed downwind.

The sink rate $V_{z}$ of a glider at constant airspeed was used to obtain the decrease of airspeed at constant height as modeled by the Rayleigh cycle. To do this the rate of change of kinetic energy $d / d t\left(m V^{2} / 2\right)=m V(d V / d t)$ at constant height was equated to the 
rate of change of potential energy $d / d t(m g h)=m g V_{z}$, at constant airspeed. The result indicates that $d V / d t=g /\left(V / V_{z}\right)$, where $V / V_{z}$ represents values of the glide ratio (glide polar). Values of the glide ratio are closely equal to values of lift/drag $(L / D)$ for $L / D$ values $>>1$ typical of glider flight. Lift $L=C l(\rho / 2) V^{2} S$ and drag $D=C d(\rho / 2) V^{2} S$.

$V / V_{z}$ is nearly constant in the relevant glider airspeed range $\Delta V$ centered a particular average airspeed, and therefore acceleration is nearly constant and airspeed decreases nearly linearly in time due to drag. For example, values of $V / V_{z}$ are within around $1 \%$ of the mean $V / V_{z}$ in the energy-neutral circle of a wandering albatross soaring with a cruise airspeed of $16 \mathrm{~m} / \mathrm{s}$. Thus, the total decrease of airspeed $\Delta V$ in a half loop ( $t / 2)$ is given by

$$
\Delta V=\frac{g t}{2\left(V / V_{\mathrm{z}}\right)}
$$

Values of $V / V_{z}$ were modeled using the aerodynamic equations of motion for balanced circular flight (Lissaman, 2005; Torenbeek and Wittenberg, 2009) and a quadratic drag law, in which the drag coefficient is proportional to the lift coefficient squared. In balanced circular flight the horizontal component of lift balances the centripetal acceleration and the vertical component of lift balances gravity. Specifically, $V / V_{z}$ was modeled by

$$
V / V_{z}=\frac{2\left(V / V_{z}\right)_{\max }}{\left(V / V_{c}\right)^{2}+\left(V_{c} / V \cos \varphi\right)^{2}}
$$

where $\left(V / V_{z}\right)_{\max }$ is the maximum glide ratio at $V_{c}$ the associated cruise airspeed (airspeed of minimum drag) of a representative glider in straight flight, $\varphi$ is the bank angle, and $\cos \varphi$ is given by

$$
\cos \varphi=\sqrt{\frac{1}{(2 \pi V / g t)^{2}+1}} .
$$

Combining Equations (A2) and (A3) with (A1) and assuming that $\Delta V=W$ indicates that 


$$
\Delta V=W=\frac{g t}{4\left(V / V_{z}\right)_{\max }}\left[\left(V / V_{c}\right)^{2}+\left(V_{c} / V\right)^{2}+\left(2 \pi V_{c} / g t\right)^{2}\right] .
$$

The $\left(2 \pi V_{\mathrm{c}} / g t\right)^{2}$ term is due to the centripetal acceleration and bank angle. Equation A4 indicates that for a particular glider (with a given $\left(V / V_{z}\right)_{\max }$ at $V_{c}$ ) in energy-neutral soaring, the increase of glider airspeed $(\Delta V)$ gained by crossing the wind-shear layer and the gradual loss in a half loop is a function of both the loop period $t$ and the average airspeed $V$.

A minimum $\Delta V$ (and minimum $W$ ) for a given glider airspeed occurs at an "optimum" loop period $t_{\text {opt }}$ coinciding with minimum energy loss in a loop (minimum $V_{\mathrm{z}} t$ ). The optimum loop period $\left(t_{\text {opt }}\right)$ was obtained by setting the derivative $d(\Delta V) / d t$ of (Eq. A4) equal to zero and solving for $t$.

$$
t_{\text {opt }}=\frac{2 \pi V_{c} / g}{\sqrt{\left(V / V_{c}\right)^{2}+\left(V_{c} / V\right)^{2}}} .
$$

Equation A5 indicates that $t_{\text {opt }}$ decreases with increasingly large $V$. In sufficient wind flight faster than the cruise airspeed $V_{c}$ can be accomplished by decreasing the loop period toward $t_{\text {opt }}$ and increasing the frequency of shear-layer crossings. Substituting Eq. A5 into Eq. A4 provides an expression for minimum $\Delta V$ (and minimum $W$ ) for a given $V$. Thus the minimum wind speed $W_{\min }$ needed for a given glider airspeed $V$ in energy neutral dynamic soaring is given by

$W_{\min }=\frac{\pi V_{c}}{\left(V / V_{\mathrm{z}}\right)_{\max }} \sqrt{\left(V / V_{c}\right)^{2}+\left(V_{c} / V\right)^{2}}$.

This equation can be used to calculate the maximum possible airspeed $V_{\max }$ for a given wind speed $W$. Eq. A6 indicates that the absolute minimum $W_{\min }$ occurs when $V=V_{c}$, and thus the equation for the absolute minimum $W_{\min }$ is 


$$
W_{\min }=\frac{\pi V_{c} \sqrt{2}}{\left(V / V_{z}\right)_{\max }}
$$

At fast glider speeds $>50 \mathrm{~m} / \mathrm{s}$ and for $V_{c} \sim 25 \mathrm{~m} / \mathrm{s},\left(V / V_{c}\right)^{2}>>\left(V_{c} / V\right)^{2}$ and $\left(V_{c} / V\right)^{2}$ can be neglected. This simplifies Eq. A.5 to

$$
t_{o p t}=\frac{2 \pi V_{c}^{2}}{g V} .
$$

Substituting Eq. A8 into Eq. A4 provides a simplified expression for minimum $\Delta V$ (and minimum $W$ ) for $V>50 \mathrm{~m} / \mathrm{s}$. Thus the minimum wind speed $W_{\min }$ needed for a given glider airspeed $V>50 \mathrm{~m} / \mathrm{s}$ in energy neutral dynamic soaring is given by

$$
W_{\min }=\frac{\pi}{\left(V / V_{z}\right)_{\max }}(V)
$$

This equation can be rearranged to provide the maximum glider airspeed $V_{\max }$ for a given wind speed $W$

$$
V_{\max }=\frac{\left(V / V_{z}\right)_{\max }}{\pi}(W)
$$

Equation A10 indicates that for fast flight (> $50 \mathrm{~m} / \mathrm{s}$ ) the maximum possible average airspeed in a Rayleigh cycle is proportional to wind speed. It is important to note that this linear relation depends on flying with an optimum loop period. Other loop periods can result in a smaller maximum airspeed for a given wind speed. Maximum lift/drag ratio $(L / D)_{\max }$ is approximately equal to the maximum glide polar $\left(V / V_{z}\right)_{\max }$ and can be substituted into the above equations. 
The diameter of a loop is given by $d=V t / \pi$. Substituting into this equation the expression for optimum loop period $t_{\text {opt }}$ in fast flight (Eq. A8) gives the optimum loop diameter $d_{\mathrm{opt}}$

$d_{o p t}=2 V_{c}^{2} / g$.

Equation A11 reveals that for fast flight the optimum loop diameter is proportional to cruise airspeed squared but is independent of glider airspeed.

The total acceleration of a glider includes centripetal acceleration and gravity and is given by the load factor, which equals $1 / \cos \varphi$ (see Eq. A3). For fast dynamic soaring, $V>$ $50 \mathrm{~m} / \mathrm{s},(2 \pi V / g t)^{2}>>1$, and the load factor is approximately equal to $2 \pi V / g t$.

\section{References}

Alerstam, T., Gudmundsson, G. A., Larsson, B., 1993. Flight tracks and speeds of Antarctic and Atlantic seabirds: radar and optical measurements. Philosophical Transactions of the Royal Society of London B 340, 55-67.

Baines, A. C., 1889. The sailing flight of the albatross. Nature 40, 9-10.

Barnes, J. P., 2004. How flies the albatross—-the flight mechanics of dynamic soaring, 2004. SAE Technical Paper 2004-01-3088, p. 18.

Bower, G. C., 2012. Boundary layer dynamic soaring for autonomous aircraft: design and validation. Ph.D. dissertation, Department of Aeronautics and Astronautics, Stanford University, unpublished.

Deittert, M., Richards, A., Toomer, C. A., Pipe, A., Engineless UAV propulsion by dynamic soaring, 2009. Journal of Guidance, Control, and Dynamics 2(5), 1446-1457. 
Idrac, P., 1925. Étude expérimentale et analytique du vol sans battements des oiseaux voiliers des mers australes, de l'Albatros en particulier. La Technique Aeronautique 16, 9-22.

Lissaman, P., 2005. Wind energy extraction by birds and flight vehicles. American Institute of Aeronautics and Astronautics Paper 2005-241, January 2005, p. 13.

Pennycuick, C. J., 2002. Gust soaring as a basis for the flight of petrels and albatrosses (Procellariiformes). Avian Science 2, 1-12.

Pennycuick, C. J., 2008. Modelling the flying bird. Academic Press, New York, p. 496.

Rayleigh, J. W. S., 1883. The soaring of birds. Nature 27, 534-535.

Richardson, P. L., 2011. How do albatrosses fly around the world without flapping their wings? Progress in Oceanography 88, 46-58.

Richardson P. L., 2012. High-speed dynamic soaring. Radio-Controlled Soaring Digest, April 2012, 29 (4), 36- 49.

Sachs, G., 2005. Minimum shear wind strength required for dynamic soaring of albatrosses. Ibis 147, 1-10.

Sachs, G., Traugott, J., Nesterova, A. P., Bonadonna, F., 2013. Experimental verification of dynamic soaring in albatrosses. Journal of Experimental Biology 216, 4222-4232.

Torenbeek, E., Wittenberg, H., 2009. Flight Physics: Essentials of Aeronautical Disciplines and Technology, with Historical Notes. Springer, New York, p. 535. 
Wakefield, E. D., Phillips, R. A., Matthiopoulos, J., Fukuda, A., Higuchi, H., Marshall, G. J., Trathan, P. N., 2009. Wind field and sex constrain the flight speeds of central-place foraging albatrosses. Ecological Monographs 79, 663-679.

Weimerskirch, H., Bonadonna, F., Bailleul, F., Mabille, G., Dell’Omo, G., Lipp, H.-P, 2002. GPS tracking of foraging albatrosses. Science 295, 1259. 